\title{
Saúde Indígena: Reflexões Contemporâneas
}

\author{
Indians Health: Contemporary Reflections
}

Salud Indígena: Reflexiones Contemporáneas

\section{Thaís Janaina Wenczenovicz}

RESUMO. Objetivo: O estudo analisa alguns elementos da trajetória sócio-histórica das políticas públicas em saúde no processo de efetivação e disponibilização deste direito fundamental social junto as Comunidades Indígenas do Brasil. Metodologia: Foi usado o método bibliográfico-interpretativo, acompanhado de dados estatísticos da Fundação Nacional do Índio, Fundação Nacional de Saúde e Instituto Brasileiro de Geografia e Estatística. Resultados: A política de saúde para os povos nativos é uma das questões de constante discussão por diversos organismos nacionais e internacionais. Sensíveis às enfermidades trazidas por não indígenas e, muitas vezes, habitando regiões remotas e de difícil acesso, as populações indígenas são vítimas de doenças como malária, tuberculose, infecções respiratórias, hepatite, doenças sexualmente transmissíveis, entre outras. Desde a criação da Fundação Nacional do Índio (Funai), em 1967, diferentes instituições e órgãos governamentais se responsabilizaram pelo atendimento aos índios. Conclusão: As diretrizes foram alteradas diversas vezes, mas, com exceção de casos pontuais, em nenhum momento a situação sanitária nas terras indígenas foi realmente satisfatória.

Palavras-chave: População Indígena. Saúde de Populações Indígenas. Direito à Saúde.

ABSTRACT. Objective: The study aims to analyze some elements of the socio-historical trajectory of public policies in health in the process of realization and social provision this fundamental right beside the indigenous communities in Brazil. Methodology: It was used the literature-interpretative method, accompanied by statistical data for the National Indian Foundation, National Health Foundation and Brazilian Institute of Geography and Statistics. Results: The health policy for native peoples is one of the issues of constant discussion by several national and international bodies. Sensitive to diseases brought by non-indigenous peoples and, many times, inhabiting remote regions and of difficult access, indigenous peoples are victims of diseases such as malaria, tuberculosis, respiratory infections, hepatitis, sexually transmissible diseases, among other. Since the creation of the National Indian Foundation (Funai), in 1967, various institutions and government agencies undertook the care for Indians.Conclusion: The guidelines were changed several times, but, except for individual cases, in no time the health situation in indigenous lands was really satisfactory.

Keywords: Indigenous Population. Health of Indigenous Peoples. Right to Health.

RESUMEN. Objetivo: El estudio objetiva analizar algunos elementos de la trayectoria sociohistórica de las políticas públicas en salud en el proceso de efectivización y disposición de este derecho fundamental social junto a las Comunidades Indígenas de Brasil. Metodología: Fue usado el método bibliográfico-interpretativo, acompañado de datos estadísticos de

\footnotetext{
${ }_{1}^{1}$ Docente adjunta e pesquisador sênior/Universidade Estadual do Rio Grande do Sul. E-mail: t.wencze@terra.com.br
} 
Fundación Nacional del Indio, Fundación Nacional de Salud y I Instituto Brasileño de Geografía y Estadística. Resultados: La política de salud para los pueblos nativos es unos de las cuestiones de constante discusión por diversos organismos nacionales e internacionales. Sensibles a las enfermedades traídas por los que no son indígenas y, muchas veces, habitando regiones remotas y de difícil acceso, las poblaciones indígenas son víctimas de enfermedades como malaria, tuberculosis, infecciones respiratorias, hepatitis, enfermedades de transmisión sexual, entre otras. Desde la creación de la Fundación Nacional del Indio (Funai), en 1967, diferentes instituciones y órganos gubernamentales se responsabilizaron por la atención a los indios. Conclusión: Las directrices fueron alteradas varias veces, pero, con excepción de casos puntuales, en ningún momento la situación sanitaria en las tierras indígenas fue realmente satisfactoria.

Palabras-Ilave: Población Indígena. Salud de Poblaciones Indígenas. Salud. Derecho a la Salud.

\section{Introdução}

O processo de ocupação e colonização das terras brasileiras fez com que grande parte das comunidades indígenas sofresse alterações em seu modo de viver. Muitas etnias foram dizimadas por completo, outras sobreviveram e alteraram totalmente seus costumes e tradições. Concomitante ao extermínio acompanhou a chegada de inúmeras doenças, até então desconhecidas pelos povos indígenas.

Milhares foram às mortes causadas por doenças infecto-contagiosas como: coqueluche, difteria, gripe, malária ${ }^{2}$, sarampo, sífilis, dentre outras. Desde o século XV ao $\mathrm{XVIII}$, as doenças permanecem ceifando vidas nas comunidades indígenas brasileiras e da América Latina.

Segundo dados do Instituto Brasileiro de Geografia e Estatísticas (1), existem no território 305 etnias indígenas que falam 274 línguas e totalizam aproximadamente 897 mil indivíduos. Sua presença é observada em todas as Unidades Federativas do Brasil e cada povo possui uma cultura própria. Esta diversidade cultural reafirma a identidade multicultural do país, bem como também consiste um desafio para a elaboração e implementação de políticas públicas específicas e diferenciadas.

A Constituição Federal do Brasil de 1988 representa uma conquista para esses grupos sociais, devido ao reconhecimento de sua cidadania e autonomia, rompendo com a tutela e a perspectiva integracionista e assimilacionista que caracterizavam o contexto jurídicopolítico do Estado até o fim da década de 80.

\footnotetext{
2 São escassos os estudos científicos que analisem a situação epidemiológica da malária entre as populações indígenas do Brasil. De uma maneira geral, as informações estão restritas ao número de casos descritos nos relatórios do antigo Serviço de Proteção ao Índio (SPI), da atual Fundação Nacional do Índio (Funai) e Conselho Missionário Indigenista (CIMI).
} 
Os indígenas possuem paridade em direitos ao conjunto de cidadãos brasileiros, além daqueles específicos garantidos pela Constituição e legislação internacional. ${ }^{3}$ Dentre eles são garantidos o respeito à sua organização social, costumes, crenças e tradições, e os direitos originários sobre as terras que tradicionalmente ocupam, competindo à União demarcá-las, protegê-las e fazer respeitar todos os seus bens, CF/88 art. 23. (2) Essa mesma Constituição define a saúde como direito de todos e dever do Estado, consolidando os princípios para a criação do Sistema Único de Saúde/SUS, CF/88 art. 196. (2)

Corroborando para o processo de zelo para com as comunidades indígenas a Declaração das Nações Unidas sobre os Direitos Indígenas (3) afirma que os povos nativos têm direito a seus medicamentos tradicionais e a manter suas práticas de saúde, incluindo a conservação de suas plantas, animais e minerais de interesse vital do ponto de vista médico. Os indígenas têm também direito ao acesso, sem qualquer discriminação, a todos os serviços sociais e de saúde. Indica também que os mesmos têm o direito de usufruir, por igual, do mais alto nível possível de saúde física e mental. Os estados tomarão as medidas que forem necessárias para alcançar progressivamente a plena realização deste direito.

O devido artigo divide-se em três partes e utiliza-se do procedimento metodológico bibliográfico-investigativo, associados a fontes com bases estatísticas e dados de organismos estatais. Atendem as exigências metodológicas os documentos legais e normativos como: o Subsistema de Atenção à Saúde dos Povos Indígenas criado em 1999, por meio da Lei no 9.836/99 (4), conhecida como Lei Arouca; dados da Funasa e Funai. Também foram consultados: Decreto $n^{0}$ 6.289/07 (5), que estabelece o Compromisso Nacional pela Erradicação do Sub-registro Civil de Nascimento e Ampliação do Acesso à Documentação Básica; a Lei n 9.534 (6) de 10 de dezembro, que trata da gratuidade dos atos necessários ao exercício da cidadania; a Lei no 6.001 de 19 de dezembro de 1973 (7), que dispõe sobre o Estatuto do Índio; o Decreto № 5.051, de 19 DE Abri de 2004 (8), que promulga a Convenção no 169 da Organização Internacional do Trabalho (OIT) sobre Povos Indígenas e Tribais e o Relatório Violência contra os povos indígenas no Brasil (9) elaborado pelo Conselho Indigenista Missionário (CIMI).

\footnotetext{
3 Dentre os documentos cita-se: a Carta das Nações Unidas, o Pacto Internacional de Direitos Econômicos, Sociais e Culturais e o Pacto Internacional de Direitos Civis e Políticos, assim como a Declaração e o Programa de Ação de Viena.
} 


\section{Sobre as comunidades indígenas no Brasil: direito e acesso à saúde}

Ao mesmo modo que os demais países da América Latina, o Brasil inicialmente foi povoado por dezenas de etnias indígenas. Em virtude da exploração colonial, os indígenas perderam suas referências materiais/estruturais, terras, fonte de sua sobrevivência e imateriais, aspectos artísticos, linguísticos e religiosos. A soma desses elementos indicou a chegada da pobreza e acarretou a deteriorização da sua condição de vida, colocando-os em uma condição de exclusão e marginalização social. Acresce-se a esse contexto o processo de colonialidade.

Quijano (10) adverte que a formação de relações sociais fundadas na ideia de inferiorização e invisibilidade produziram na América identidades sociais historicamente novas: índios, negros e mestiços, e redefiniu outras. Assim, termos com espanhol e português, e mais tarde europeu, que até então indicavam apenas procedência geográfica ou país de origem, desde então adquiriram também, em relação às novas identidades, uma conotação racial. E na medida em que as relações sociais que estavam configurando eram relações de dominação e tais identidades foram associadas às hierarquias, lugares e papéis sociais correspondentes, com constitutivas delas, e, consequentemente, ao padrão de dominação que se impunha. Em outras palavras, raça e identidade racial foram estabelecidas como instrumentos de classificação social básica da população.

Posteriormente, foram absorvidos pelos processos de aculturação, assimilação, integracionismo, que corroboraram com o processo de marginalização e subalternização dos indígenas. Para Spivak (11), o sujeito subalterno é aquele cuja voz não pode ser ouvida ou permanece silenciado. Também costumeiramente aparece como constituição de mais um "outro", uma classificação essencialista que acaba por não incorporar a noção de différance ou hibridismo.

Nessa mesma linha, Dussel argumenta que a modernidade, assentada e iniciada nos pilares do colonialismo, justifica uma 'práxis irracional da violência' (12). Por consequência a violência torna-se uma constância na cotidianidade cristalizando-se por séculos nas comunidades indígenas.

Em alguns países, a exemplo do Brasil, o Estado demarcou terras indígenas em todo o território nacional, com o objetivo de lhes garantir a subsistência. No entanto, em muitos casos, o tamanho da reserva (terra indígena) não é suficiente para abrigar todas as 
comunidades nativas com dignidade, colocando-os novamente em condição de marginalização e exclusão.

Sabe-se que o surgimento do Brasil como Estado foi moldado pela ideologia nacional como forma de garantir sua unidade territorial, política, jurídica e econômica, mesmo com a existência dos diferentes grupos étnicos distribuídos em diversas regiões do país. Como corolário dessa ideologia, em relação aos povos indígenas impôs-se uma política assimilacionista, ${ }^{4}$ ou integracionista, cujo objetivo era a integração do indígena à comunhão nacional até que, pouco a pouco, não existissem mais indígenas no Brasil e o povo brasileiro 'tornar-se-ia uma nação homogênea e uniforme'.

No decorrer da história, as diversas comunidades indígenas vão, lentamente, passando da invisibilidade construída no século XIX para o protagonismo conquistado e restituído nos séculos $X X$ e $X X I$ por movimentos políticos e intelectuais nos quais eles próprios têm tido intensa participação. No longo contato com os vários agentes sociais com os quais conviviam, os indígenas aldeados desenvolveram suas próprias formas de compreensão sobre a nova realidade na qual se inseriam sobre os direitos que lhes haviam sido concedidos e sobre as suas possibilidades de ação para obtê-los.

Historicamente, no Brasil, os primeiros cuidados com a saúde registrados aos grupos tribais com intervenção externa partiram das missões religiosas. ${ }^{5}$ Posteriormente, com a criação do Serviço de Proteção ao Índio, na primeira década do século XX, o atendimento médico aos grupos indígenas passou a ser atribuição desta agência governamental. A responsabilidade do Estado foi reafirmada no Estatuto do índio que assegurou aos mesmos "o regime geral da Previdência Social"; "os meios de proteção à saúde facultado à comunhão nacional" e "especial assistência dos poderes públicos em estabelecimentos a esse fim destinados" (arts. 54 e 55).

Confalonieri (13) destaca a possibilidade de distinção - singularidades e peculiaridades, no que tange ao trabalho em saúde em comunidades nativas, destacando-se as seguintes:

a) Situação de Transculturação - dentro da questão mais ampla do processo aculturativo, observado com intensidade e rapidez variáveis após o contato com a sociedade não índia envolvente, a transculturação no campo da saúde surge pela introdução de um conjunto de princípios e práticas do sistema

\footnotetext{
${ }^{4}$ A política indigenista do Estado brasileiro incorporou e acentuou a proposta de promover a assimilação dos índios e extinguir antigas aldeias coloniais que havia sido introduzida pelas reformas pombalinas, em meados do século XVIII.

${ }^{5}$ Entretanto, sabe-se que o cuidado com a saúde anterior a chegada do colonizador ocorria nas próprias terras indígenas como uma extensão cultural e religiosa. Para essa temática ver: Langdon EJ. Participação e Autonomia nos Espaços Interculturais de Saúde Indígena: reflexões a partir do sul do Brasil.
} 
médico oficial em comunidades que vêm lidando com as questões de saúdedoença através de sistemas tradicionais de crenças e práticas de cura. A sobreposição destas duas medicinas envolve conflitos de compatibilização e aceitação tanto por parte dos receptores como dos executores das ações. Neste contexto, tem papel fundamental a intermediação antropológica no acompanhamento dos programas de saúde e, principalmente, na formação de pessoal de saúde - índios e não índios - para atuação em comunidades indígenas. $O$ instrumental conceitual da antropologia médica ao elucidar a concepção indígena do organismo humano, da causalidade das doenças e das terapêuticas da medicina tradicional, subsidia e possibilita o processo de integração controlada entre os dois sistemas médicos.

b) Situação Geográfica - a maioria das comunidades indígenas brasileiras se localiza em regiões distantes da Amazônia e Centro-Oeste, com aldeias mais ou menos esparsas e de baixa densidade demográfica. Isto implica dificuldades de acesso que, aliadas à deficiência da infra-estrutura local e recursos, contribuem para a descontinuidade na execução das ações e programas. Neste contexto, toma-se imprescindível um sistema de comunicações permanente com outros níveis de referência. A elevação dos custos operacionais, principalmente em função da dificuldade de manutenção de equipamentos e instalações, além da grande dependência do transporte aéreo é outro aspecto a ser considerado. Uma outra consequência é a dificuldade de permanência prolongada de equipe de saúde não-índia nestas áreas em virtude do isolamento social e profissional e ausência de comodidades das áreas urbanas.

c) Dinâmica do Perfil Epidemiológico - é conhecido o rápido ciclo de adaptação às enfermidades antes desconhecidas por grupos tribais isolados do contato com a sociedade não indígena e que sofrem grandes transformações aculturativas em seus hábitos e condições de vida. De uma situação inicial de equilíbrio por convívio secular com processos infecciosos de caráter endêmico e baixa letalidade, iniciam-se surtos de viroses introduzidas, com alta morbidade e mortalidade e importantes repercussões na organização social. Se superada esta fase, com a continuidade da reprodução biológica, inicia-se uma nova etapa na qual prevalecem os problemas dentários e os processos infecciosos da "aculturação parcial" tais como infecções cutâneas, tuberculose, DST, diarreia, malária etc. Estes resultam principalmente da sedentarização forçada, do desequilíbrio alimentar, padrão inadequado de higiene individual e contato mais íntimo com as populações urbanas.

Acresce-se também outra etapa que completa a "transição epidemiológica", a qual ocorre com a maior integração à sociedade envolvente e as perdas e aquisições culturais decorrentes, caracterizando-se pelo aumento das doenças crônico-degenerativas (câncer, hipertensão, diabetes etc.) com o surgimento de um perfil de morbi-mortalidade mais próximo ao da sociedade não indígena. Tal se deve basicamente ao estresse social, à aculturação alimentar radical e à exposição a poluentes ambientais e produtos industrializados. É também característico desta fase o surgimento de um maior índice de doenças mentais (alcoolismo, suicídio) resultantes da desintegração social e marginalidade 
econômica, que explicam a participação dos acidentes e violências como as mais importantes causas de mortalidade em grupos largamente aculturados. (14) (15)

De modo significativo, registra-se o aumento da mortalidade infantil, dos casos de desnutrição grave, de suicídios entre os jovens, do consumo intenso de bebida alcoólica não indígena e da adoção ilegal de crianças indígenas visando em certos casos à escravidão doméstica. A discriminação étnico-racial sofrida durante as estadas na cidade pode ser vista como crítica e causadora da forte omissão das instituições locais no acolhimento e apoio a essas populações. Além disso, os abusos e práticas dolosas de instituições financeiras somam-se às práticas análogas à escravidão por dívida realizada por comerciantes locais por meio de retração de cartões e senhas bancárias, cadernetas de dívidas e incentivo ao consumo abusivo de bebidas alcoólicas. ${ }^{6}(16)$

Dados da Secretaria Especial de Saúde Indígena (Sesai) (17), do Relatório Violência contra os Povos Indígenas no Brasil e do $\mathrm{Cimi}^{7}$ (9) mostram a ocorrência de 87 suicídios entre os povos indígenas, em 2015. Os dados enviados pela Sesai estão distribuídos pelos Distritos Sanitários Especiais Indígenas (Dsei), instâncias responsáveis pelo atendimento à saúde nas comunidades indígenas. Dada a limitação das informações, não é possível fazer análises mais adequadas sobre as ocorrências em todo o país.

Segundo dados da Sesai $^{8}(17)$, houve 45 casos de suicídios somente no estado de Mato Grosso do Sul, sendo $73 \%$ entre o sexo masculino e $27 \%$ entre o sexo feminino. A faixa etária com maior número de casos é a dos 15 aos 19 anos (37\%), seguido de casos na faixa de 10 a 14 anos (24\%) e 20 a 29 anos (22\%). O maior número constata-se no município de Amambai (37\%). Também preocupa a quantidade de casos registrados na região Norte do país, em áreas de abrangência dos Dsei de Amapá e Norte do Amapá (1), Alto Rio Negro (8), Alto Rio Solimões (13), Leste de Roraima (8), Médio Rio Solimões (2) e

\footnotetext{
${ }^{6}$ Os autores falam acerca dos indígenas Hupd'äh e os Yuhupdëh que habitam a região do Alto Rio Negro (AM), na fronteira entre o Brasil e a Colômbia. As comunidades Hupd'äh situam-se às margens de igarapés da área interfluvial dos rios Tiquié e Papuri, afluentes da margem esquerda do rio Uaupés. Já as comunidades do povo Yuhupdëh estão distribuídas ao longo do rio Tiquié nas áreas interfluviais, havendo concentrações nos igarapés Castanha, Ira, Cunurí, Samaúma e no rio Apaporis. Os dados demográficos mais atuais estimam a população Hupd'äh num total de 1.500 indivíduos distribuídos em aproximadamente 35 aldeias, enquanto os Yuhupdëh seriam compostos por aproximadamente 1.000 indivíduos.

7 É um organismo vinculado à CNBB criado em 1972, quando o Estado brasileiro assumia abertamente a integração dos povos indígenas à sociedade majoritária como única perspectiva. O Cimi procurou favorecer a articulação entre aldeias e povos, promovendo as grandes assembleias indígenas pela garantia do direito à diversidade cultural. Dentre seus princípios que fundamentam a ação do Cimi observa-se: - o respeito à alteridade indígena em sua pluralidade étnico-cultural e histórica e a valorização dos conhecimentos tradicionais dos povos indígenas; - o protagonismo dos povos indígenas sendo o Cimi um aliado nas lutas pela garantia dos direitos históricos; - a opção e o compromisso com a causa indígena dentro de uma perspectiva mais ampla de uma sociedade democrática, justa, solidária, pluriétnica e pluricultural.

${ }^{8}$ Secretaria Especial da Saúde Indígena.
} 
Yanomami (2), totalizando 32 suicídios. Notam-se casos de suicídios em áreas de abrangência do Dsei Tocantins (2). Além dos casos informados pela Sesai, os regionais do Cimi registraram suicídios no Acre (1), em Mato Grosso (1) e no Paraná (4), entre os povos Kulina, Karajá e Guarani, respectivamente (9). O reconhecimento dos modos de viver e se relacionarem com os grupos não indígenas, com base em dados estatísticos e através dos perfis de morbi-mortalidade que se implantaram concomitante aos processos de transformação socio-cultural, bem como a expectativa de continuidade deste processo, colocam os administradores, gestores de serviços de saúde e lideranças indígenas em situação de preparação para reduzir o impacto destes fenômenos nos níveis de saúde das comunidades nativas.

\section{Direito à saúde: breves reflexões}

O direito à saúde é debate em diversas áreas do conhecimento: antropologia, direito, educação, física, medicina, dentre outras. O mesmo vem sendo analisado há séculos, tanto no Brasil quanto internacionalmente, porém, foram os dois últimos séculos que o debate aproximou os anseios da sociedade e o Estado. A sociedade passou a ver o direito à saúde como grupo dotado de direitos e valores a serem respeitados e garantidos. $O$ resultado dessa nova postura trouxe ao Estado à responsabilidade de oferecer condições mínimas de vida e de sobrevivência a todos sem distinção, elevando a responsabilidade do Estado como garantidor de direitos fundamentais, especialmente do direito à saúde.

Segundo Figueiredo (18) a noção de que a saúde constitui um direito humano e fundamental, passível de proteção e tutela pelo Estado, é resultado de uma longa evolução na concepção não apenas do direito, mas da própria ideia do que seja a saúde, em si mesma considerada.

Para Novelino (19) "a saúde é indissociável do direito à vida e da dignidade da pessoa humana", sendo ainda direito fundamental social e integrante do mínimo existencial da pessoa humana. Sabe-se que não é possível haver saúde sem a preservação da vida, da dignidade e o bem-estar de cada indivíduo. Vinculando-se diretamente ao princípio da dignidade humana, é direito de todos que estiverem em território brasileiro independente de sua nacionalidade, sendo o Estado o principal responsável, respondendo os entes federativos solidariamente no que concerne à saúde, não isentando a família e a sociedade de suas responsabilidades que juntamente se obrigam. 
Pregno (20) diz:

[...] la tensión entre utilidad y justicia exige siempre resolver de alguna manera. Conscientes de lo espinoso de la cuestión y de que no todo lo que resulta útil puede estimarse justo, arriesgamos que un criterio para adjetivar como justo un curso de acción en materia sanitaria quizá sea la observancia -en algún grado- de ciertos niveles de utilidad. Vale decir: no necesariamente la utilidad reclama a la justicia, pero sí ésta a aquélla; ergo, intuimos que entre las condiciones de la justicia, presumible mente, figure la realización de la utilidad. No obstante, a todo evento, debe quedar en claro que no se trata de introducir variables que acaben por ercantilizar la salud sino de acusar recibo de la finitud de los recursos, so pena de embriagarse en un idealismo capaz de abonar la peregrina idea de que todo cuanto se desea resulta posible.

\section{Panorama sobre o sistema e subsitema de atenção à saúde dos povos indígenas no Brasil}

Sabe-se que a primeira organização a atuar internacionalmente com o objetivo específico de melhorar as condições de saúde e de qualidade de vida das pessoas é a Organização Pan-Americana da Saúde (OPAS), que hoje reúne quarenta e oito países e atua como Escritório Regional da Organização Mundial da Saúde para as Américas. A devida organização tem por objetivo central garantir condições de igualdade no que cerne 0 acesso à saúde, combater doenças, melhorar a qualidade de vida e elevar a expectativa de vida dos povos das Américas.

Posteriormente, postulam no rol de instituições e documentos a Organização das Nações Unidas (ONU) e a Declaração dos Direitos Humanos (DUDH) de 1948 e a Declaração de Direitos Humanos de Viena de 1993. Estabelecendo assim uma diversidade de direitos sociais e evidentemente o direito à saúde, fruto da internacionalização dos Direitos Humanos.

A partir dos documentos declaratórios de direitos humanos, o Estado brasileiro passa a considerar na segunda metade do século $X X$ a saúde como um direito fundamental. Teve como marco a Constituição Federal brasileira de 1988, no que se refere à garantia dos direitos fundamentais, a qual trata em seu Título II - Dos Direitos e Garantias Fundamentais, no Capítulo II, trata "Dos Direitos Sociais", e Título VIII "Da Ordem Social”, no Capítulo II, "Da Seguridade Social”, a Constituição Aborda o Direito Fundamental à Saúde no primeiro artigo da Seção II, afirmando que é "direito de todos e dever do Estado". (16)

A República Federativa do Brasil, enquanto Estado Democrático de Direito, conforme previsão na Carta Constitucional fundamenta-se em aspectos como: cidadania, dignidade e soberania popular. Assim, a saúde passa a ser declarada como um direito fundamental de 
cidadania, cabendo ao Estado a obrigação de provê-la a todos os cidadãos, indistintamente. (21)

Desta forma, o Estado de Direito passa do modelo tradicional de Estado Liberal de Direito para o Estado Democrático de Direito, resultando em um aprofundamento dos direitos humanos e fundamentais, que ganham novos valores, e a atuação do Estado passa a ser reivindicada positivamente (22). Segundo Dallari e Fortes (23), o direito à saúde, antes entendido como obrigação moral, passa a ser transformado em obrigação legal.

De acordo com a redação do art. 6º da Constituição Federal de 1988 (2) incorpora-se a saúde como direito social, a ser garantido através de prestações positivas pelo Estado:

Art. 6o São direitos sociais a educação, a saúde, a alimentação, o trabalho, a moradia, o lazer, a segurança, a previdência social, a proteção à maternidade e à infância, a assistência aos desamparados, na forma desta Constituição. ${ }^{9}$

A saúde nas palavras de Paulo Bonavides é um dos bens mais precisos do ser humano, in verbis:

Os Direitos Sociais fizeram nascer a consciência de que tão importante quanto salvaguardar o indivíduo, era proteger a instituição brasileira. A saúde encontra-se entre os bens intangíveis mais preciosos do ser humano, digna de receber a tutela protetiva estatal, porque se consubstancia em característica indissociável do Direito à Vida. (24)

Partindo de uma análise do período pré e pós Constituição Federal de 1988, o Brasil evoluiu significativamente no que se refere ao Direito à Saúde, tendo em vista que anterior a Constituição não era dever constitucional do Estado (em todas as esferas: União, Estados, Distrito Federal e Municípios) assegurar os direitos relativos à saúde e hoje deve fazer parte das políticas públicas do governo, inclusive com orçamento mínimo a ser destinado para políticas públicas relativas à saúde.

Em países como o Brasil, que não atingiram o mesmo nível de proteção social que o dos continentes precursores da ideia de direitos sociais, o período atual gera outros problemas, como a redução de gastos públicos com políticas sociais, o que significa o não comprometimento com a meta do bem-estar social.

\footnotetext{
${ }^{9}$ Conforme o art. 23, II, a União, os Estados, o Distrito Federal e os Municípios possuem competência comum para cuidar da saúde. O art. 24, inciso XII, define que, "compete à União, aos Estados e ao Distrito Federal legislar concorrentemente sobre: [...] matérias que tratam da proteção e defesa da saúde". Compete ainda, conforme art. 30, VII, aos Municípios, com a cooperação técnica e financeira da União e dos Estados prestar serviços de atendimento à saúde da população.
} 
A proteção social é afetada diretamente pelas crises econômicas e políticas, bem como pelo mau uso do dinheiro público na aplicação da saúde. As distorções no uso dos recursos é presença em vários países da América Latina. No que se refere às políticas de saúde, estudos comparativos sobre as mudanças recentes nos países latino-americanos ainda são relativamente escassos, embora alguns autores já tenham destacado os efeitos nocivos das reformas das décadas de 1980 e 1990 sobre os sistemas de saúde da região ou ressaltado a existência de diferentes modelos de sistema. (25)

Na América Latina existem cerca de 45 milhões de indígenas que representam 8,3\% da população da região. ${ }^{10} \mathrm{Na}$ última década, foram constatadas melhorias no acesso à saúde e à educação, no reconhecimento de seus direitos territoriais e sua participação política, entretanto as políticas públicas seguem avançado para fins de resgatar direitos fundamentais negados por décadas.

Um dos aspectos apontados como positivos sobre a política pública de saúde às comunidades indígenas brasileiras é relativa à vacinação. A Política Nacional de Atenção à Saúde dos Povos Indígenas (26), aprovada em 2002, estabelece que o modelo de atenção tenha como base o perfil epidemiológico da população indígena e prioriza as ações de promoção à saúde, além de prevenção e controle de doenças e agravos, tendo a vacinação como uma das ações mais importantes da atenção primária à saúde, pois possui impacto no nível individual e coletivo, contribuindo significativamente para a redução da mortalidade infantil.

Por isso, considerando as especificidades desses povos, o calendário básico de vacinação disponibilizado pelo Programa Nacional de Imunizações foi modificado, ampliando não apenas a quantidade de vacinas ofertadas (atualmente 14), mas também as faixas etárias de aplicação de algumas dessas vacinas (Hepatite B, Varicela, Influenza e Pneumocócica 23-valente), tendo sido atualizado em 19 de julho de 2013, por meio da Portaria Ministerial no 1.498/2013. (27)

A vacinação oferecida aos indígenas é considerada uma ação universal, tendo em vista que abrange toda a população e está disponível em todos os DSEI, e transversal já que acompanha o ciclo de vida do indivíduo. A implementação das ações de imunização nas aldeias pode ser complexa, não apenas devido a fatores como diversidade cultural,

\footnotetext{
${ }^{10}$ Relatório da Comissão Econômica para a América Latina e o Caribe (CEPAL), 2014.
} 
localização geográfica, rotatividade dos profissionais contratados, dificuldade para realizar coleta, registro e análise dos dados, condições especiais necessárias para o acondicionamento, conservação e transporte dos imunobiológicos, mas também devido às dificuldades dos DSEI para desenvolver, de forma integral, a atenção primária à saúde dos povos indígenas, otimizando as entradas das equipes nas aldeias. (27)

Mesmo com as dificuldades encontradas pelo DSEI na execução das ações de vacinação nas aldeias, diversos aspectos contribuíram para o êxito obtido nesse resultado e demais atividades de imunização realizadas, dentre os quais, destacam-se: periodicidade das ações, qualificação profissional, recursos financeiros, parcerias com outros níveis de gestão e outras instituições e disponibilidade adequada de equipamentos e transporte. No entanto, apesar de se observar um aumento do indicador pactuado, nem os dados apresentados nem o desenvolvimento dessas ações são homogêneos entre os Distritos, pois depende da capacidade executora de cada um que, por sua vez, está diretamente relacionado tanto à estruturação da SESAI, no nível central, como nos próprios Distritos. De uma forma geral, pode-se observar um impacto positivo na redução da morbi-mortalidade por doenças imunopreveníveis na população indígena. (28)

\section{Saúde e Povos Indígenas}

O Subsistema de Atenção à Saúde dos Povos Indígenas foi criado em 1999, por meio da Lei no 9.836/99 (4), conhecida como Lei Arouca. Ele é composto pelos Distritos Sanitários Especiais Indígenas/Dseis que se configuram em uma rede de serviços implantada nas terras indígenas para atender essa população, a partir de critérios geográficos, demográficos e culturais. Seguindo os princípios do SUS, esse subsistema considerou a participação indígena como uma premissa fundamental para o melhor controle e planejamento dos serviços, bem como uma forma de reforçar a autodeterminação desses povos.

O propósito dessa Política consiste em:

[...] garantir aos povos indígenas o acesso à atenção integral à saúde, de acordo com os princípios e diretrizes do Sistema Único de Saúde, contemplando a diversidade social, cultural, geográfica, histórica e política de modo a favorecer a superação dos fatores que tornam essa população mais vulnerável aos agravos à saúde de maior magnitude e transcendência entre os brasileiros, reconhecendo a eficácia de sua medicina e o direito desses povos à sua cultura $[. .].(29)$ 
Para o alcance desse propósito são estabelecidas as seguintes diretrizes, que devem orientar a definição de instrumentos de planejamento, implementação, avaliação e controle das ações de atenção à saúde dos povos indígenas:

- organização dos serviços de atenção à saúde dos povos indígenas na forma de Distritos Sanitários Especiais e Pólos-Base, no nível local, onde a atenção primária e os serviços de referência se situam;

- preparação de recursos humanos para atuação em contexto intercultural;

- monitoramento das ações de saúde dirigidas aos povos indígenas;

- articulação dos sistemas tradicionais indígenas de saúde;

- promoção do uso adequado e racional de medicamentos;

- promoção de ações específicas em situações especiais;

- promoção da ética na pesquisa e nas ações de atenção à saúde envolvendo comunidades indígenas;

- promoção de ambientes saudáveis e proteção da saúde indígena;

- controle social.

A política de descentralização do atendimento aos indígenas no Brasil é de 1999. O acordo consolidou-se mediante a assinatura de convênios com prefeituras e instituições da sociedade civil, reduzindo assim a ação direta do Estado, a qual implementou 34 Distritos Sanitários Especiais Indígenas (DSEls). Mesmo abrangendo uma grande área territorial, o subsistema vagarosamente foi apresentando alguns resultados positivos.

O subsistema de saúde indígena do Sistema Único de Saúde era então gerido pela Fundação Nacional de Saúde (Funasa), que, durante anos, foi alvo de denúncias ligadas à corrupção e deficiências no atendimento. Entretanto, o movimento indígena, por meio da dialogicidade angariou a possibilidade de que a gestão da saúde indígena fosse gerenciada por uma secretaria específica, diretamente vinculada ao Ministério da Saúde. Essa demanda se concretizou em 2010. Surge a partir de então os Distritos Sanitários Especiais Indígenas (DSEI). (30)

Os DSEls são, atualmente, de responsabilidade da Secretaria Especial de Saúde Indígena (Sesai), e foram delimitados a partir de critérios epidemiológicos, geográficos e etnográficos. Cada DSEI possui um conjunto de equipamentos que permite a realização do 
atendimento de casos simples, ficando as ocorrências de alta complexidade a cargo de hospitais regionais, implicando em um aparato para remoção dos doentes.

O controle social destes Distritos ocorre por meio dos Conselhos Indígenas de Saúde (Condisi), que garantem, ao menos no plano da legislação, a participação dos indígenas na gestão dos DSEls. Os conselheiros são escolhidos pelas comunidades atendidas e participam de reuniões periódicas organizadas pelos gestores de cada DSEI. Na prática, a relação entre os povos indígenas e esses gestores é tensa, permeada por problemas relacionados à gestão e a aplicação de recursos. (31)

A Fundação Nacional do Índio possui a missão institucional de coordenar a política indigenista do Estado brasileiro, bem como proteger e promover os direitos, em especial à terra, à preservação do meio ambiente e à promoção do desenvolvimento sustentável, que impactam nos determinantes do processo saúde-doença e na qualidade de vida desses povos.

Também estabelece o que diz respeito ao direto a atenção à saúde, de acordo com o Decreto no 7.778 de 27 de julho de 2012 (32), que a mesma monitore as ações e serviços de atenção à saúde indígena. Esse acompanhamento contribui para o fortalecimento do Subsistema, na garantia do direito à atenção diferenciada e na valorização nas medicinas tradicionais indígenas.

De acordo com o relatório da Secretaria Especial de Saúde Indígena, enquanto marco legal pode-se apontar como principais documentos que regem as ações e a gestão da Saúde Indígena:

- Leis o 8.080, de 19 de setembro de 1990, e o 9.836, de 23 de setembro de 1999, que dispõem sobre as condições para a promoção, proteção e recuperação da saúde, a organização e o funcionamento dos serviços correspondentes e dá outras providências, instituindo o Subsistema de Atenção à Saúde Indígena.

- Decreto no 3.156, de 27 de agosto de 1999, que trata das condições para a prestação de assistência à saúde dos povos indígenas, no âmbito do Sistema Único de Saúde, pelo Ministério da Saúde.

- Portaria/MS no 1.163, de 14 de setembro de 1999, a qual versa sobre as responsabilidades na prestação de assistência à saúde dos povos indígenas, no Ministério da Saúde e dá outras providências. 
- Norma que rege o controle, o monitoramento e a vigilância da qualidade da água para consumo humano e seu padrão de potabilidade:

- Portaria/MS no 2.914/2011, que trata dos procedimentos de controle e de vigilância da qualidade da água para consumo humano e seu padrão de potabilidade.

- Outras normas legais que disciplinam a qualidade da água:

- $\quad$ Lei no 9.433, de 08 de janeiro de 1997.

- Decreto ํㅜ 5.440, de 04 de maio de 2005.

- Lei no 11.445, de 05 de janeiro de 2007.

- Resolução Conama n 357, de 07 de março de 2005.

- Resolução Conama no 396, de 03 de abril de 2008.

- Resolução Conama no 430, de 13 de maio de 2011.

Mesmo com a evolução e inclusão das comunidades indígenas nas políticas públicas e acesso ao direito à saúde, o Cimi registrou 52 casos de desassistência na área da saúde nos seguintes estados: Acre (2), Amapá (1), Amazonas (2), Bahia (1), Maranhão (11), Mato Grosso (5), Mato Grosso do Sul (4), Minas Gerais (1), Pará (9), Rio de Janeiro (1), Rio Grande do Sul (1), Rondônia (3), Roraima (2), Santa Catarina (2), São Paulo (2) e Tocantins (5). (9)

A título de exemplo pode-se citar um caso ocorrido em abril de 2015 , no estado do Rio Grande do Sul, mais especificamente na cidade de Mato Castelhano tendo como motivo de denúncia a falta de atendimento médico na cidade.
VÍTIMA: Comunidade
POVO: Kaingangue
TERRA INDIGENA: Mato Castelhano
MUNICÍPIO: Mato Castelhano
DESCRIÇÃO: A prefeitura do município de Mato Castelhano se nega a utilizar recursos previstos em uma portaria estadual que garante atendimento qualificado à saúde indígena. Em uma decisão judicial de primeira instância, o juiz alegou que os indígenas ocupavam terras de maneira irregular e que, por conta disso, não haveria razão para a prefeitura ser obrigada a fazer uso dos recursos. Segundo uma procuradora da República, essa atitude revela um "tipo de preconceito velado", porque o argumento da prefeitura local é de que, como não há terra indígena oficialmente reconhecida, os índios ali residentes não teriam direito a um tratamento diferenciado na área de saúde. Contudo nem a lei e nem a portaria condicionam o exercício desse direito à regularização fundiária. Foi dito em sentença que os indígenas eram atendidos juntamente com o restante da população local através do SUS. O estado do Rio Grande do Sul, com base na portaria no 41/2013, disponibilizou o valor de $\mathrm{R} \$ 4$ mil mensais ao município em prol dos índios, mas a prefeitura se nega a utilizar os recursos. A procuradora da República informa que a recusa municipal em utilizar os recursos é ilegal, pois impede que os índios 
tenham acesso a "um serviço que constitui a materialização de um direito fundamental social".

Há também casos de morte por desassistência à saúde, nos estados do Acre (1), Pernambuco (1) e Roraima (1). Em Pernambuco, uma adolescente apresentou sintomas semelhantes à chikungunya e foi a óbito. Segundo a comunidade Xukuru, $60 \%$ dos indígenas apresentaram os mesmos sintomas como edemas, dores no corpo e na cabeça, manchas e coceira. Na aldeia vivem 250 pessoas inseridas em 61 famílias. Nessa região há poucos médicos e em casos de emergência, os indígenas precisam se dirigir para o hospital municipal, onde nem sempre são atendidos. Outro vetor de doenças é a qualidade da águia ingerida pelos indígenas. A maioria ingere água não potável e, a água que chega através dos órgãos públicos chega por meio de caminhão-pipa, sendo armazenada em baldes e tonéis, possíveis criadores de mosquitos. (9)

\section{Conclusão}

Dos elementos centrais dessa análise, comunidades indígenas e saúde, observa-se que o direito à saúde está diretamente relacionado ao direito à vida, sendo indissociável do Princípio de Dignidade da Pessoa Humana. Esse possui previsão constitucional, na condição direito social, com status privilegiado, sendo direito de todos, devendo ser efetivado mediante políticas públicas emitidas por parte do Estado, englobando neste termo todos os entes da Federação.

Em se tratando de comunidades vulneráveis no Brasil é possível apontar que essas vivenciam situações de exclusão, invisibilidade e discriminação que, em última instância, as colocam em posição de maior vulnerabilidade frente a uma série de agravos. Corroboram com essa afirmação os coeficientes de morbi-mortalidade mais altos do que os registrados em nível nacional; fome e desnutrição, riscos ocupacionais e violência física e simbólica que são apenas alguns dos múltiplos reflexos sobre a saúde decorrentes da minimização social.

Com base nesses indicadores, tornar-se-á possível melhor compreender a gênese, determinantes e formas de reprodução das desigualdades em saúde, já que esses elementos são fundamentais para o embasamento de atuações políticas, inclusive por parte de lideranças indígenas, e de intervenções com vistas à promoção da eqüidade em saúde. 
O direito à saúde para as comunidades nativas e aos povos originários referenda a resposta a uma longa trajetória histórica de busca na efetivação desse direito. Em muitas vezes o impulso na busca pelo acesso e garantia ao direito à saúde foi enfrentada devido à presença das epidemias e pandemias que afetava a população, a qual interferia, na ordem cultura, social e econômica e de sobrevivência dos inúmeros grupos étnicos, ganhando espaço com políticas públicas, consolidadas pela Constituição Federal de 1988.

\section{Referências}

1. Instituto Brasileiro de Geografia e Estatítica. Disponível em: https://www.ibge.gov.br/. [Acesso em 15.nov.2017]

2. Brasil. Constituição República Federativa do Brasil de 1988. Brasília: Senado Federal, 1988.

3. Nações Unidas. Declaração das Nações Unidas sobre os Direitos Indígenas. Disponível em: http://www.un.org/esa/socdev/unpfii/documents/DRIPS pt.pdf. [Acesso em 20.nov.2017].

4. Brasil. Lei no 9.836, de 23 de setembro de 1999. Acrescenta dispositivos à Lei no 8.080 , de 19 de setembro de 1990, que "dispõe sobre as condições para a promoção, proteção e recuperação da saúde, a organização e o funcionamento dos serviços correspondentes e dá outras providências", instituindo o Subsistema de Atenção à Saúde Indígena. Disponível em: http://www.planalto.gov.br/ccivil 03/leis/19836.htm [Acesso em 7.nov.2017].

5. Brasil. Decreto no 6.289 de 6 de dezembro de 2007. Estabelece o Compromisso Nacional pela Erradicação do Sub-registro Civil de Nascimento e Ampliação do Acesso à Documentação Básica, institui o Comitê Gestor Nacional do Plano Social Registro Civil de Nascimento e Documentação Básica e a Semana Nacional de Mobilização para o Registro Civil de Nascimento e a Documentação Básica. Disponível em: http://www.planalto.gov.br/ccivil 03/ ato2007-2010/2007/decreto/d6289.htm [Acesso em 20.nov.2017]

6. Brasil. Lei $n^{\circ} 9.534$ de 10 de dezembro de 1997. Dá nova redação ao art. 30 da Lei no 6.015, de 31 de dezembro de 1973, que dispõe sobre os registros públicos; acrescenta inciso ao art. 1ㅇ da Lei no 9.265, de 12 de fevereiro de 1996, que trata da gratuidade dos atos necessários ao exercício da cidadania; e altera os arts. 30 e 45 da Lei no 8.935, de 18 de novembro de 1994, que dispõe sobre os serviços notariais e de registro. Disponível em: http://www.planalto.gov.br/CCivil 03/leis/L9534.htm [Acesso em 20.nov.2017]

7. Brasil. Lei no 6.001 de 19 de dezembro de 1973. Dispõe sobre o Estatuto do Índio. Disponível em: http://www.planalto.gov.br/ccivil 03/leis/L6001.htm [Acesso em 20.nov.2017] 
8. Brasil. Decreto № 5.051 de 19 de abril de 2004. Promulga a Convenção № 169 da Organização Internacional do Trabalho - OIT sobre os povos Indígenas e Tribais.

Disponível em: http://www.planalto.gov.br/ccivil 03/ ato2004-

2006/2004/decreto/d5051.htm [Acesso em 10.nov.2017]

9. Conselho Indigenista Missionário. Relatório Violência contra os Povos Indígenas no Brasil - Dados de 2015. Brasília, 2016. Disponível em:

https://www.cimi.org.br/observatorio-da-violencia/relatorio-2016/ [Acesso em 11.nov.2017].

10. Quijano A. Colonialidad y modernidad-racionalidad. Disponível em:

http://pt.scribd.com/doc/36091067/Anibal-Quijano-Colonialidade-e-Modernidade-

Racionalidade [Acesso em: 15.ago. 2017].

11. Spivak, GC. Pode o Subalterno Falar? Belo Horizonte: Editora UFMG, 2010.

12. Dussel E. Europa, modernidad y eurocentrismo. In: La colonialidad del saber: eurocentrismo y ciencias sociales, perspectivas latinoamericanas. Buenos Aires: Clacso, 2000.

13. Confalonieri UEC. O Sistema Único de Saúde e as populações indígenas: por uma integração diferenciada. In: Cadernos de Saúde Pública; 1989, 5(4). Disponível em http://www.scielo.br/scielo.php?script=sci arttext\&pid=S0102-311X1989000400008. [Acesso em 9.nov.2017].

14. Young TK. Mortality patterns of isolated Indians in northwestern Ontario. Publ. Health Rep., 1983; 98:467-475.

15. Rhoades ER et al. The Indian Burden of IIIness and Future Health Interventions. Publ. Health Rep., 102(4):361-368.

16. Lima AP, Marques B, Ramos D. Violações de Direitos de povos indígenas de recente contato: o caso dos Hupd'äh e dos Yuhupdëh região do Alto Rio Negro (AM). In: Revista Aracê - Direitos Humanos em Revista. 2016; 3(4). Disponível em: https://arace.emnuvens.com.br/arace/article [Acesso em 11.nov.2017].

17. Ministério da Saúde. Disponível em: http://portalsaude.saude.gov.br. [Acesso em 8.nov.2017].

18. Figueiredo MF. Direito fundamental à saúde: parâmetros para sua eficácia e efetividade. Porto Alegre: Livraria do Advogado, 2007.

19. Novelino M. Manual de Direito Constitucional. Rio de Janeiro: Forense, 2013.

20. Pregno E. Todo, para todos y grátis: coordenadas para garantizar la inviabilidade de um sistema de salud. In: Revista de Direito Sanitário. 2016;17(2):176-186. Disponível em: http://www.revistas.usp.br/rdisan [Acesso em 9.nov.2017]. 
21. Silva K, Tanaka OY. Direito à saúde e integralidade: uma discussão sobre os desafios e caminhos para sua efetivação. In: Revista Interface: Comunicação Saúde Educação. 2012; 16(40):249-259.

22. Luiz O, Kayano J. Saúde e direitos: princípios para ação. In: BIS, Bol. Inst. Saúde. 2010; 12(2):115-21.

23. Dallari SG, Fortes RAC. Direito sanitário: inovação teórica e novo campo de trabalho. In: Fleüry, S. (org.). Saúde e democracia: a luta do CEBES. São Paulo: Lemos 1997.

24. Bonavides P. A Constituição aberta. Belo Horizonte: Del Rey, 1993.

25. Fleüry, S. Saúde e democracia: a luta do CEBES. São Paulo: Lemos, 1997.

26. Costa DC. Política Indigenista e Assistência à Saúde. Noel Nutels e o Serviço de Unidades Sanitárias Aéreas. In: Cadernos de Saúde Pública. 1986; 4(3):388-401.

27. Ministério da saúde. Portaria Ministerial n 1.498, de 19 de julho de 2013. Redefine o Calendário Nacional de Vacinação, o Calendário Nacional de Vacinação dos Povos Indígenas e as Campanhas Nacionais de Vacinação, no âmbito do Programa Nacional de Imunizaçãoes (PNI), em todo o território Nacional. Disponível em:

http://portalarquivos2.saude.gov.br/images/sismob2/pdf/programa-imunizacao/PORTARIA1498-DE-19-DE-JULHO-DE-2013.pdf. [Acesso em 13.nov.2017].

28. Ministério da Saúde. Relatório de Gestão do exercício de 2013. Brasília, 2014. Disponível em: http://conselho.saude.gov.br. [Acesso em 10.nov.2017.

29. Fundação Nacional do Índio. Coletânea da Legislação Indigenista Brasileira. Brasília, 2010. Disponível em: http://www.funai.gov.br/arquivos. [Acesso em 12.nov.2017]

30. Fundação Nacional do Índio (Funai). Coletânea da Legislação Indigenista Brasileira. Brasília: Imprensa Oficial, 2016. Disponível em: http://www.funai.gov.br/arquivos [Acesso em 12.nov.2017]

31. Brasil. Ministério da Saúde. Relatório de Gestão do exercício de 2016. Disponível em: http://portalarquivos.saude.gov.br/images/pdf/2017/abril/26/RG-SESAI-2016-VersaoFinal.pdfr. [Acesso em 10.nov.2017]

32. Brasil. Decreto no 7.778 de 27 de julho de 2012. Aprova o Estatuto e o Quadro Demonstrativo dos Cargos em Comissão e das Funções Gratificadas da Fundação Nacional do Índio. Disponível em: http://www2.camara.leg.br/legin/fed/decret/2012/decreto7778-27-julho-2012-773975-norma-pe.html [Acesso em 13.nov.2017] 
Cuadernos Iberomericanos

de Derecho Sanitario

Recebido em:11.12.2017

Aprovado em: 6.3.2018

\section{Como citar este artigo:}

Wenczenovicz TJ. Saúde Indígena: Reflexões Contemporâneas. Revista Cadernos Ibero-Americanos de Direito Sanitário. 2018 jan./mar, 7(1):63-82. 